\title{
LER É TÃO BOM! A LEITURA DA LITERATURA...
}

\section{READING IS SO GOOD! LITERATURE READING...}

\author{
Norma Sandra de Almeida Ferreira ${ }^{1}$ \\ Lilian Lopes Martin da Silva ${ }^{2}$
}

\begin{abstract}
Resumo: O objetivo deste artigo é trazer alguns movimentos de análise a partir da interlocução com dois textos que discursam sobre a educação em leitura para jovens leitores, na atualidade. Uma história em quadrinhos (Estúdio Maurício de Souza, 2018), que consideramos um gênero e suporte bastante presentes tanto no ambiente escolar como no mercado editorial e que busca alcançar o público infantil; a Base Nacional Comum Curricular - BNCC (versão final, 2018), no que diz respeito à área de linguagens - Língua Portuguesa - para os $1^{\circ}$ e $2^{\circ}$ Anos do Ensino Fundamental 1, no campo de atuação humana denominado artístico-literário. Destacamos e interpretamos alguns pontos comuns em ambos os textos, argumentando o modo como eles constroem um discurso em torno da "leitura literária", reafirmando-a como uma habilidade individual relevante e de grande importância a ser adquirida na nossa sociedade: ler é bom! Nessa visão, para ambos, a leitura é vista desencarnada dos suportes a que está vinculada. Como prática (da linguagem), a leitura é aliada a valores, afetos, sensibilidades, memórias, conhecimentos e também à habilidades e se faz nas comunidades de leitores (na escola, inclusive) que a colocam em evidência e a põem em movimento, de forma partilhada e diversa, em condições (desiguais) de produção, de recepção e circulação.
\end{abstract}

Palavras-chave: Leitura; literatura; BNCC.

Abstract: The purpose of this article is to present some analysis movements based upon the dialogue with two texts that discuss reading education for young readers nowadays. A comic book (Estúdio Maurício de Souza, 2018), which we consider a genre and support that is very present both in the school environment and in the publishing market and that seeks to reach children; the National Common Curricular Base - BNCC (final version, 2018), with regard to the area of languages - Portuguese Language - for the 1st. and 2nd. Years of Elementary School 1 , in the field of human performance called artistic-literary. We highlight and interpret some common points in both texts, arguing the way they build a discourse around "literary reading", reaffirming it as a relevant and important individual skill to be acquired in our society: reading is good! In this view, for both, reading is seen disembodied from the supports to which it is linked. As a practice (of language), reading is combined with values, affections, sensitivities, memories, knowledge and also skills and is made in communities of readers (at school, inclusive) that put it in evidence and set it in motion, shared and diverse form, in (unequal) conditions of production, reception and circulation.

Keywords: Reading; literature; BNCC.

O objetivo deste artigo é trazer alguns movimentos de análise a partir da interlocução com dois textos que discursam sobre a educação em leitura para jovens leitores, na atualidade. Uma história em quadrinhos (Estúdio Maurício de Souza, 2018), que consideramos um gênero e suporte bastante presentes tanto no ambiente escolar como no mercado editorial e que busca alcançar o público infantil; a Base Nacional Comum Curricular - BNCC (versão final, 2018),

\footnotetext{
${ }^{1}$ Universidade Estadual de Campinas.

${ }^{2}$ Universidade Estadual de Campinas.
} 
no que diz respeito à área de linguagens - Língua Portuguesa - para os $1^{\circ}$ e $2^{\circ}$ Anos do Ensino Fundamenal 1, no campo de atuação humana denominado artístico-literário.

Tanto a história em quadrinhos como a BNCC estão em circulação desde o final do ano de 2018, produzem e disseminam sentidos sobre modos de conceber a leitura e, por consequência, a formação de leitores, os modos de ler e os suportes em que a leitura e a escrita se materializam. São discursos bastante distintos - enquanto origem, gênero e destinação - mas que colaboram para uma única concepção de leitura: como sendo algo universal (aparentemente igual em quaisquer condições e para todos os leitores) e uma habilidade individual a ser apreendida pelo sujeito. Tais produções são vinculadas a instituições que têm força de autoridade ou poder de grande penetração junto a um amplo público, como a mídia, editoras e instituições oficiais que produzem materiais destinados ao ambiente escolar.

Pela não neutralidade de tais discursos, somos impelidos a colocar diante deles, questões, desejos e posições, chamando para a interlocução alguns outros estudos (CORAZZA, 2016; MARSIGLI et al., 2017).

\section{Ler é tão bom! Uma tirinha}

Na tirinha "Ler é tão bom"3 Cebolinha está levemente sorrindo e bastante concentrado no tablet, anda (sem olhar para os lados ou para o chão), em direção da Monica, que sentada em uma árvore, segura um livro entre as mãos e ri ("hi, hi, hi!!"), provavelmente por causa da história que lê. Cebolinha senta-se ao lado dela e inicia um diálogo: "adolo ler no tablet. Ouvi dizer que o livlo implesso plejudica o meio ambiente". Mônica, com cara de espanto e surpresa, levanta os olhos do livro e diz com "segurança": a professora falou que o papel é fácil para reciclar! Eletrônicos é que são mais difícies!” Cebolinha também se espanta e se surpreende com esta informação. Interrompida a leitura de ambos, Mônica enfatiza argumentos a favor do suporte que carrega o seu texto: "papel é feito de matéria prima renovável! Eletrônicos são feitos de matéria prima não renovável! E os eletrônicos gastam energia para funcionar!"

As falas dos personagens remetem a 'pesos' desiguais. $\mathrm{O}$ argumento de Cebolinha baseiase no ter "ouvido dizer" enquanto o de Mônica reproduz as informações dadas por sua professora - adulta, 'portadora' do saber. A argumentação de ambos se sustenta por um ponto de vista bastante caro às novas gerações: a sustentabilidade do nosso planeta. $E$, infere-se - pela quantidade de argumentos e pela legitimidade da autoria - um tom de autoridade a favor do impresso em relação ao digital.

O objeto que Mônica segura nas mãos é visivelmente um livro de muitas páginas, capa dura e sem ilustração. Um objeto símbolo da leitura prestigiada. Seria um livro de Maurício de Souza? O tablet "esconde" para os leitores da tirinha, o gênero lido por Cebolinha. Seriam tirinhas, uma revista em quadrinhos ou um livro? Não importa!

Não importa também o conteúdo da leitura que realizam. Provavelmente uma história de humor ou algo bem descontraído, que permite pausas para diálogos com outros leitores, também envolvidos na mesma prática e habitando o mesmo espaço. É de se supor que um tratado filosófico ou um texto enciclopédico exigiriam, por exemplo, outras posturas, gestos e talvez outros instrumentos (lápis para anotações), além de lugares ou espaços mais apropriados para eles.

\footnotetext{
${ }^{3}$ Publicada na Revista Grande Encontro Turma da Mônica \& Liga da Justiça, O níver, n. 44, dezembro de 2018, Editora Maurício de Souza, Panini Comics Brasil, Barueri, SP, p. 47. O gibi é composto de 66 páginas, cinco histórias e quatro tirinhas e ainda, com propagandas todas elas ligadas às produtos e produções do Estúdio Maurício de Souza. Interessante notar que todas as histórias estão impressas em letra bastão, nos títulos, falas dos narradores e dos personagens. Exceções apenas nos nomes dos personagens (Mônica, Cebolinha - na forma script e de Tina, por exemplo, na forma cursiva), nos títulos das histórias.
} 
Houve tempo, em que as leituras que provocam devaneios podiam levar à loucura, a pensamentos libertinosos, à ociosidade. Houve e há tempos em que conteúdos são criminalizados como pervertores de mentes inocentes ou estimuladores de violências e de preconceitos. É perigoso ler!!

Em nosso caso, não parece haver temor pela finalidade da leitura: uma leitura prazerosa é o que fazem [Mônica inicia a história rindo do que lê e Cebolinha embora mais comedido também tem um sorriso no rosto]. Não é a leitura-estudo, leitura-consulta de informações, uma leitura pretexto para a escrita de um texto, por exemplo, mas uma leitura sem compromisso.

A tirinha não parece ter a intenção de problematizar as modalidades de leitura adotadas pelos personagens: individual e silenciosa; sentado ou em pé, apoiado na árvore; movimentada pelo passar de folhas de papel (barulho, tato) ou pelos dedos que tocam a tela etc. Historicamente, as modalidades não só mudam, como ainda são mais ou menos condenáveis.

Os leitores são crianças, provavelmente, também como é o público pressuposto para este material. Um menino, que ainda faz trocas na fala entre o /r/ e o /1/ e uma menina. Leitores diversos para suportes também distintos, como são diferentes a idade, escolarização, temperamento entre eles e ainda, suas famílias etc. São amigos que dividem e disputam brincadeiras e que compartilham afinidades como o gostar de ler e de atribuir importância à leitura. Aprenderam a gostar de ler? Com quem, onde, quando, como?

No final, buscando o desfecho, em um ambiente que busca manter-se amistoso (ambos estão sorridentes), Cebolinha pergunta: “quer saber de uma coisa?" e Mônica se dispõe a ouvir a resposta, dizendo: "manda!" Cebolinha então conclui: "Ler é muito legal! Seja em eletlônicos ou implessos! O que Mônica concorda: "É isso aí!”. FIM.

O final da história reafirma o discurso hegemônico em torno da leitura - ler é bom - em que a prática carrega a importância, relevância e valorização em si mesma, independentemente do que se lê, como se lê, para quê e em que suporte.

Em uma sociedade escriturística como a nossa, ninguém constestaria este final e tampouco colocaria em questão a prática da leitura, em uma revista voltada para pequenos leitores que foi lançada inicialmente impressa, e que, hoje, se apresenta em suportes distintos próprios da contemporaneidade, disputando espaços no mercado editorial voltado para crianças. Afinal a produção de Maurício de Souza pode ser encontrada hoje no site (http://turmadamonica.uol.com.br/), com assinaturas das revistas, leituras de tirinhas e de revistas, jogos, crônicas e passatempos, on-line ou através de dowlowds. Enquanto mercadoria a ser consumida, adquirida e mantida em circulação, a história em quadrinhos precisa manter-se competitiva, antenada no tempo dos seus leitores, que como Cebolinha, podem ter preferência pela leitura, em tablet, podem simultaneamente querer ler, nas formas impressa e digital.

O conflito, responsável por desencadear o enredo, é montado entre ler no papel ou na tela: o suporte está em questão. Situa-se em um discurso social que aponta para um temor sobre o fim do livro, da revista, do jornal impresso e para a convivência simultanea de dois suportes na contemporaneidade. Não se pergunta: Ler o quê, como, por quê e para quê "é bom"? Quem tem acesso à leitura na tela, em nosso país? Tanto faz ler na tela ou no impresso? Quem defende a importância da leitura e por quê? Forma-se leitor independentemente do suporte do texto?

A "moral"da tirinha é explícita: ler é bom. Como poderia uma revista que pode ser vista na tela ou lida no impresso constestar tal afirmação?! E ela (con) afirma uma representação ${ }^{4}$ da prática da leitura, bastante comum nos discursos da mídia, da escola, da academia.

\footnotetext{
${ }^{4}$ Para Chartier (1990), as representações construídas do mundo social, embora aspirem à universalidade de um diagnóstico fundado na razão, são sempre determinadas pelos interesses do grupo que as forja, pelos discursos proferidos e de acordo com a posição de quem os utiliza. São modos distintos de dar inteligibilidade ao mundo, às construções e a determinada realidade social em diferentes lugares e momentos e produzidas pelas disposições
} 


\section{Ler é tão bom! A BNCC}

A Base Nacional Comum Curricular (BNCC) apresenta princípios educativos já assumidos em outros documentos, atualizando-os. ${ }^{5}$ É o caso dos Parâmetros Curriculares Nacionais - PCN $(1998)^{6}$, para os quais a linguagem é "uma forma de ação interindividual orientada para uma finalidade específica; um processo de interlocução que se realiza nas práticas sociais existentes numa sociedade, nos distintos momentos de sua história" (BRASIL, 2018, p. 67).

Seguido a mesma direção, a Base afirma adotar a perspectiva "enunciativo-discursiva" em que as atividades humanas realizam-se nas práticas sociais, mediadas por diferentes linguagens: verbal (oral ou visual-motora, como Libras, e escrita), corporal, visual, sonora e, contemporaneamente, digital. Por meio dessas práticas, as pessoas interagem conhecimentos, atitudes e valores culturais, morais e éticos, constituem-se sujeitos sociais e criam novas formas de lidar com seu tempo, como por exemplo, com a tecnologia e com linguagens produzidas pelas minorias.

Para ela, "os conhecimentos sobre os gêneros, os textos, a língua, a norma-padrão, as diferentes linguagens (semioses) devem ser mobilizados em favor do desenvolvimento das capacidades de leitura, produção e tratamento das linguagens" (BRASIL, 2018, p. 67), ampliando as possibilidades de participação dos estudantes em práticas contemporâneas (ligadas às tecnologias digitais da informação e comunicação) de diferentes campos de atividades humanas, “(...) sem o que a participação nas esferas da vida pública, do trabalho e pessoal pode se dar de forma desigual.” (BRASIL, 2018, p. 67).

$\mathrm{Na}$ BNCC o ensino da linguagem está organizado nos eixos da oralidade (fala e escuta), leitura, escrita e conhecimento linguístico/semiótico. Cada um deles no interior de diferentes campos de atividades humanas (da vida cotidiana, vida pública, do artístico-literário, de estudo e pesquisa) e de circulação dos discursos.

Nesse documento, o campo artístico-literário é definido como um campo de atuação relativo à participação dos estudantes em situações de leitura, fruição linguística, que favoreçam experiências estéticas. São apresentados como alguns gêneros deste campo, por exemplo: lendas, mitos, fábulas, contos, crônicas, canção, poemas, poemas visuais, cordéis, quadrinhos, tirinhas, charge/ cartum, dentre outros.

Diferentemente dos demais campos (da vida cotidiana ou pública, de pesquisa e estudo), o artístico-literário tem como centralidade intencional oferecer aos estudantes uma

estáveis e partilhadas, próprias do grupo, num campo de concorrências e de competições cujos desafios se enunciam em termos de poder e de dominação.

${ }^{5}$ A BNCC dá continuidade e está em consonância, com pelo menos, cinco documentos nacionais: Constituição Federal (1988); Lei de Diretrizes e Bases da Educação (1996); Diretrizes Nacionais; Parâmetros Curriculares (1998); Plano Nacional de Educação (2014). Para Marsiglia et al. (2017), a BNCC é exigência não só desses documentos anteriores, mas também de pressões internacionais. Agências, como Organização para Cooperação e Desenvolvimento Econômico (OCDE), a União das Nações Unidas para a Educação (UNESCO) e o Fundo Monetário Internacional (FMI) buscam determinar o contexto atual das políticas públicas e "definir" em uma perspectiva sistêmica diretrizes de políticas nacionais (documentos curriculares, normas e resoluções) para regular e gestar a educação (sistemas de avaliação e metas por meio do Índice de Desenvolvimento da Educação Básica), em um espaço de conflitos, disputas de interesses, de acordos e adaptações. (BITTENCOURT, 2017).

${ }^{6}$ Muitos dos principais elaboradores da BNCC, especialmente da última versão, estavam presentes também na produção desses documentos anteriores, desde os anos 90. Para a elaboração da BNCC foram reunidos representantes de diversas áreas do conhecimento das universidades públicas do país, do Conselho Nacional dos Secretários de Educação (Consed), da União Nacional dos Dirigentes Municipais da Educação (Undime), da classe empresarial - Fundação Itaú Social, Fundação Lemann, Fundação Roberto Marinho, Instituto Unibanco, Instituto Ayrton Senna, Instituto Natura, CENPEC - que se articularam no chamado "Movimento pela Base Nacional Comum", em defesa da educação de qualidade e dos direitos de aprendizagem para todos. 
produção cultural ligada ao mundo da arte e "(...) evidenciar a condição estética desse tipo de leitura e de escrita." (p. 138).

Quais justificativas ou explicações, podemos inferir da leitura da BNCC sobre a presença e permanência da literatura neste currículo escolar, por todos os anos que compõem o Ensino Fundamental e a Educação Básica? Que concepções de literatura podem estar orientando sua presença no currículo, em um campo de atuação específico (artístico-literário) e que tem como objeto de conhecimento: "a formação do leitor literário e apreciação estética e do estilo desta linguagem"? (BRASIL, 2018, p. 110).

Talvez, uma explicação seja a força da tradição do ensino da literatura no ensino da língua portuguesa ou o fato do vestibular ter como um dos seus conhecimentos a serem avaliados, a literatura. Talvez uma visão de educação mais "integral" com vistas a atender seres em formação seja uma outra explicação. Ou, também uma educação que englobe várias dimensões (psicológica, social, intelectual, física, emocional, cultural) e que capacite as crianças e jovens para diferentes atuações em campos de atividade humana e para uma significativa compreensão do mundo, dos outros, de si mesmos. Ou ainda, quem sabe, seja uma justificativa para a presença do ensino da literatura no currículo proposto pela Base, a força da representação da literatura como arte em sua “(...) dimensão humanizadora, transformadora e mobilizadora” (Brasil, 2018, p. 138).

Todas essas justificativas - explícitas ou não no documento - em torno do ensino da leitura literária têm sido fortalecidas também pelas discussões, das últimas décadas, em defesa de uma formação literária que considera as hibridizações e cruzamentos próprios da produção, recepção e circulação das manifestações culturais. Na BNCC, a formação do leitor literário contempla, ao mesmo tempo, "(...) o cânone, o marginal, o culto, o popular, a cultura de massa, a cultura das mídias, a cultura digital, as culturas infantis e juvenis, (...)" (BRASIL, 2018, p. 70), de forma a garantir uma ampliação de repertório cultural e uma interação e trato com o diferente, no respeito a distintas identidades, saberes e manifestões de diferentes comunidades. ${ }^{7}$

A presença da literatura se sustenta ainda na BNCC, talvez, pelas finalidades e práticas que $\mathrm{o}$ currículo anuncia. Este documento propõe que as práticas de leitura, de fruição e de produção de textos ligados à literatura possam evidenciar a condição e experiência estética e tornar possível que os estudantes desvendem as múltiplas camadas de sentidos dos textos, respondendo às suas demandas e firmando pactos de leitura. (p. 138). São práticas aceitas consensualmente na sociedade porque apontam possibilidades (carregadas de valores positivos) de apreciação e fruição estética, crítica e transformadora de uma produção que se faz diversa, cultural e linguisticamente. "Ler é bom!" é o mote nos dicursos políticos, da mídia e da sociedade em geral. Não se pergunta, porém: "Ler é bom"? O quê, quando, como, por que, para quê e para quem?

\footnotetext{
${ }^{7} \mathrm{~A}$ BNCC tem gerado críticas em um contexto de disputa por ideias e posições teóricas e políticas entre diferentes grupos de pesquisadores. Questiona-se, por exemplo, essa visão multiculturalista que orienta a BNCC, por influência dos pesquisadores pós-modernos, tem sido criticada pelos estudiosos da Pedagogia Histórico - Crítica. Para eles, essa aparente defesa da diversidade cultural, inclusão e solidariedade legitima a ideologia do capitalismo contemporâneo e da política neoliberal. Essa posição segundo a Pedagogia Histórico-Crítica adota uma aceitação "natural” e igual das relações de poder, levando a um conformismo social, desvalorizando a ciência e produzindo o sucateamento da escola. Revela a ausência de uma análise e denúncia de como as discriminações afetam a construcão dos conhecimentos, valores e identidades nas instituições escolares. (MARSIGLIA, 2017). Por outro lado, critica-se a possibilidade de um país como o nosso falar de uma identidade nacional ou de uma base nacional comum. O Brasil tem dimensões transculturais, desigualdade econômica, geográfica, cultural, em que alguns sujeitos detêm mais poder na produção, circulação e recepção das ideias e produtos enquanto outros vivem à margem, com desvalorização profissional, má remuneração e em condições precárias de trabalho, de lazer, de convívio familiar. (CORAZZA, 2016).
} 


\section{As práticas de linguagem: leitura e escuta na formação do leitor literário}

Nosso interesse são as propostas da BNCC para as práticas de linguagem, especificamente aquelas identificadas como leitura e escuta, vivenciadas no campo artísticoliterário, para os $1^{\circ}$ e $2^{\circ}$ anos do Ensino Fundamental 1, da Educação Básica. ${ }^{8}$

Queremos refletir o quê esse currículo aponta como objetos de conhecimentos e habilidades, no interior das práticas de leitura e de escuta, que podem ser mobilizadoras do uso e reflexão específicos da linguagem (da literatura) e que se propõem a oferecer uma apreciação e experiência estéticalestilo, através de uma fruição crítica e não superficial, no campo de atuação artístico-literário. O que é enfatizado, nesse currículo, que aponta para a formação do leitor fruidor da literatura, ao longo da Educação Básica e, especialmente, nos primeiros dois anos iniciais do Ensino Fundamental1? Que experiência estética e visão transformadora conforme apregoa o documento - podem ser inferidas através do estudo desse currículo de Língua Portuguesa, em relação às práticas de linguagem denominadas de leitura e escuta que se organizam, como autônoma e compartilhada, para os dois primeiros anos do EF?

$\mathrm{Na} \mathrm{BNCC}$, as práticas de leitura/escuta, tanto para $1^{\circ}$ quanto para o $2^{\circ}$ anos, têm o seguinte objeto de conhecimento: "apreciação estética/estilo" (p. 110) seguido das habilidades: "Apreciar poemas e outros textos versificados, observando rimas, sonoridades, jogos de palavras, reconhecendo seu pertencimento ao mundo imaginário e sua dimensão de encantamento, jogo e fruição" (BRASIL, 2018, p. 111). Deste modo, para essas práticas, o currículo elege como prioridade, nos dois primeiros anos, a poesia, tanto em sua estrutura composicional formal (rimas, sonoridades, jogos de palavras etc.) como na dimensão lúdica, imaginativa, de encantamento e de fruição, comumente atribuída a esse uso da linguagem.

Entretanto, essa "apreciação estética/estilo" dos poemas parece se limitar às habilidades de "observação" e de "reconhecimento" das características que seriam próprias e intrínsecas ao gênero, sem consideração aos suportes em que estão inscritos e às práticas de leitura e de escuta que promovem e movimentam os (distintos) sentidos dos textos. Apreciar poemas para reconhecê-los em sua estrutura formal permite conhecer o seu pertencimento ao mundo imaginário e de encantamento? Apreciar uma quadrinha em um livreto de cordel configura-se da mesma forma que apreciar um poema de Manoel de Barros em um livro impresso? Quantos sentidos podemos construir para esse verbo "apreciar" quando enraizamos os poemas em distintas comunidades de leitores, em diferentes suportes que os carregam e nas práticas - de produção e recepção - que movimentam valores, gostos, sentimentos, habilidades, finalidades etc?

Apenas para o $\mathbf{2}^{\mathbf{0}}$ ano, as práticas de leituralescuta têm como objeto de conhecimento a formação do leitor literário (p. 110) e as seguintes habilidades: "Ler e compreender, com certa autonomia, textos literários, de gêneros variados, desenvolvendo o gosto pela leitura" (BRASIL, 2018, p. 111). Assim, apenas para o segundo ano, o repertório literário para leitura e escuta é ampliado para outros gêneros, além dos textos em versos. Por que limitar o primeiro ano aos poemas, "impedindo-o" de interagir com outros gêneros de textos que, à semelhança dos primeiros, têm dimensão lúdica e imaginativa, etc? Os textos em versos e os poemas teriam outra finalidade no $1^{\circ}$ Ano, além da fruição? Por que apenas no $2^{\circ}$ ano, o currículo pressupõe a habilidade de leitura e de compreensão com autonomia e estendida a gêneros diversos? Por que esta distinção e associação entre os objetos de conhecimento e os anos de escolaridade apreciação estéticalestilo para o $1^{\circ}$ ano e formação do leitor literário para o $2^{\circ}$ ?

\footnotetext{
${ }^{8}$ No campo artístico-literário, além da prática de leitura/escuta, autônoma e compartilhada que visa a educação do leitor de literatura, o documento propõe as seguintes práticas: da escrita autônoma e compartilhada e a de estudos linguísticos/semióticos. (p. 110-111). As duas últimas práticas não serão objeto de estudo, neste texto.
} 
A formação do leitor literário, como sabemos, é algo que se aprende e se ensina culturalmente, na relação do indíviduo (desde que nasce) com os textos e seus suportes e, também, com outros leitores. A construção do gosto, de certa apreciação estética/estilo implica uma prática de leitura e escuta que coloca os leitores em contato com os objetos de leitura e com outros leitores de modo frequente, regular e em situações diversas de recepção e de produção de sentidos, de forma que ao longo do tempo, esses leitores podem construir familiaridade e intimidade com os objetos e as histórias que narram. Como ignorar que nos anos anteriores, a criança em contato com a literatura em sua diversidade de gêneros, suportes e práticas não iniciou seu processo de formação de leitor literário e de construção do gosto ou de apreciação estéticalestilo?

O que se vê, neste desenho do documento é, portanto, uma concepção de leitura no campo das habilidades e a distribuição de cada uma dessas habilidades - de forma fragmentada e descritiva - pelos anos escolares, sugerindo que, desta forma, a definição do que ensinar e avaliar seria mais fácil. Quer na sala de aula, quer nas avaliações em larga escala. ${ }^{9}$

Concordamos que a apreciação/estilo e a formação do leitor literário - objetos de conhecimento previstos pelo currículo - podem ser mobilizados diante da exposição dos alunos a uma diversidade de gêneros na prática leitura e escuta, o que nos parece ser fundamental na formação do leitor literário. No entanto, ao situar tal prática da linguagem no campo das habilidades e apenas em algumas, como "identificar", "observar", "reconhecer", as condições efetivas do ler e escutar anulam um outro caminho teórico e metodológico - o caminho das práticas da linguagem - potencializador de movimentos possíveis na produção de sentidos pelos leitores dos textos e contrariando, dessa forma, o proposto nas páginas introdutórias do currículo de LP da BNCC (p. 67-92).

Ao sustentar uma apreciação/estilo e formação do leitor literário na qual parece prevalecer (apesar de discurso em contrário) uma visão estrutural e formal da língua, portanto, limitadora, o currículo omite possibilidades no que diz respeito à diversidade de interações possíveis entre alunos e obras na compreensão (que não se faz de forma automática ou de pura transferência), gerando, assim, um comprometimento em sua percepção dos textos, em seu pertencimento ao mundo imaginário e em sua dimensão de encantamento, jogo e fruição. Exclui perguntas ou hipóteses possíveis de serem trabalhadas sobre as condições de produção desses textos que, provavelmente interferem no desenvolvimento do gosto pela leitura de certos gêneros e não outros e na compreensão dos modos como os sujeitos interagem por meio das palavras, imagens, sons, gestos e movimentos entre si e na relação com o mundo.

Está ausente, portanto, da BNCC, uma perspectiva dialógica constitutiva de um texto literário, em que se busca por efeitos de recepção singulares, desviantes, problematizadores pelos leitores que se distinguem entre si. Uma perspectiva dialógica na qual os sujeitos que estão usando a linguagem em diferentes situações previstas para a prática de leitura e de escuta, acolhem ou argumentam pontos de vistas diferentes, comunicam ideias, emoções, sentimentos, valores, expectativas, na exposição e contato com a diversidade dos gêneros em prosa e em verso, na apreciação estéticalestilo e na formação do leitor literário, objetos previstos nas práticas de leitura e escuta.

\footnotetext{
${ }^{9}$ Hoje a ênfase curricular e didática dada nas salas de aula às supraestruturas textuais - separadas e desvinculadas das práticas da leitura e da escrita, das ações e situações em cujo contexto elas têm sentido - cristaliza e superficializa o objeto de ensino da língua: as práticas. Substitui-se a descrição gramatical tradicional pela identificação do formato do gênero no trabalho com o texto. “(...) Ensinar as características supraestruturais próprias de cada gênero é muito mais econômico - ocupa muito menos tempo da aula - do que trabalhar sobre problemas próprios de cada texto particular e sobre os conteúdos linguísticos que contribuem para resolvê-los." (Lener, 2002, p. 57), e principalmente sobre as condições de produção e de recepção de tais textos.
} 
Se estendermos nosso olhar, percorrendo as páginas da BNCC, para além das práticas de leitura podemos inferir os aspectos privilegiados pelo currículo no todo do campo artísticoliterário. Nas práticas da escrita, compartilhada e autônoma, e nas práticas de análise linguística/ semiótica, as habilidades previstas reforçam o ensino - de forma escalonada entre os primeiros anos - focado na composição formal dos textos escutados, lidos e imaginados e daqueles baseados em livros de imagens.

A ênfase na estrutura composicional dos textos lidos funciona como "modelo" para a escrita (reconto) de textos narrativos, quer de forma individual e autônoma ( $2^{\circ}$ ano), quer tendo o professor como escriba ( $1^{\circ}$ ano). Uma estrutura composicional que orienta a prática de análise linguística/semiótica para o reconhecimento dos elementos formais que compõem o gênero em prosa (enredo, conflito, personagens, tempo e espaço) ou em versos (rimas, sonoridades, associações com sensações), ou ainda, nos textos poéticos-visuais (formato do texto na páginas, efeitos visuais), de autores reconhecidos (não de alunos).

Assim, as práticas de leitura e escuta, funcionam apenas como "pretextos" para garantir o trabalho com a identificação e recuperação dos elementos das formas composicionais dos textos narrativos e dos poéticos nas outras duas práticas. O currículo não estimula, por exemplo as práticas de leitura e escuta, como exercício de autoria construída no jogo dos recursos expressivos da linguagem e na possibilidade de produção de sentidos com o texto original e com os outros já lidos junto aos leitores. Uma prática de leitura e de escuta que funcionaria também deste modo nas práticas de escrita (por exemplo, espontânea das crianças) ou de análise linguística/semiótica (nos textos dos alunos). Um "esquecimento" de que uma velha história ouvida ou lida não se resume a mero reconto, quer oral, quer escrito. Poderiam ser tantas histórias recontadas quanto o forem seus autores!!! ${ }^{10}$

Em nenhuma dessas práticas de linguagem - leitura e escuta, escrita, análise linguística/semiótica -, o currículo coloca em questão a multiplicidade de problemas e soluções de cada texto particular, não considera suas situações particulares de construção e compreensão de determinado gênero ligado em suas condições de produção e suporte que o sustenta, nos diversos campos de atuação da linguagem (no caso, campo artístico-literário). ${ }^{11}$

O currículo, especialmente, o destinado aos $1^{\circ}$ e $2^{\circ}$ anos do Ensino Fundamental 1, no campo artístico-literário, omite práticas culturais ${ }^{12}$ diretamente e igualmente importantes para o desenvolvimento dos objetos de conhecimentos previstos - apreciação/estilo e a formação do leitor literário - especialmente nas situações de leitura e escuta, tais como:

1. Frequentar lugares de guarda de livros (livrarias, biblioteca), espetáculos, exposições culturais e museus, saraus, em que os leitores são educados em gestos adequados e necessários a tais experiências;

2. Estimular conversas e escutas, de modo que os alunos possam comparar, analisar, discutir pontos de vista e impressões, estilos de composição, formas de se criar poeticamente os dramas e utopias humanas representadas pela literatura, em diferentes lugares e tempos;

\footnotetext{
${ }^{10}$ Segundo Geraldi (2015), tal como está proposto no currículo na BNCC, “(...) recontar uma história pode ser um bom exercício de memória, mas não é um bom exercício de escrita! (p. 390) porque produzir um texto exige construir uma interlocução (ação da linguagem) entre leitores. E complementamos, uma interlocução de autoria.

${ }^{11}$ Um currículo que enfatiza o ensino da estrutura formal composicional dos textos narrativos e poéticos, seja na leitura, escrita e análise linguística e que privilegia questões como: qual é o personagem? o que é um conflito? presta-se segundo Bittencourt (2017) para homegeneizar, ordenar e regular a obtenção de resultados mais facilmente "cobrados" e avaliados pela escola e pelas avaliações em grande escala, como o PISA, por exemplo.

${ }^{12}$ Citaremos, a título de exemplos, algumas práticas culturais de leitura e escuta ligadas mais diretamente aos impressos, suporte de textos selecionado para análise neste artigo.
} 
3. Propor situações e lugares para exposições de leitura feitas, para troca e empréstimos de livros;

4. Articular a diversidade de gêneros a distintas práticas de leitura e escuta: silenciosa, oral, na forma de jogral, mediada pela palavra ledora da professora etc., acompanhada de livros ou de memória, por exemplo;

5. Vivenciar poemas em prosa e em versos em diferentes suportes de textos: livros impressos; oralizados, memorizados, digitalizados etc.

Práticas culturais que não são meros procedimentos didáticos ou estratégias para uma aprendizagem mais significativa. Práticas culturais entendidas como objetos de conhecimento a serem ensinados e aprendidos intencionalmente na escola e previstos no currículo.

Se voltarmos às finalidades do campo artístico-literário, apontadas no referencial teórico que abre o Documento, pouca consistência encontramos quando olhamos para um currículo calcado no desenvolvimento de (poucas e redundantes) habilidades que aparecem explicitadas e diretamente ligadas apenas às formas composicionais dos textos literários. Podemos afirmar que tal como estão propostas as práticas de leitura e escuta (também reforçadas pelas práticas de escrita e análise linguística/semiótica), o currículo reduz a "experiência/vivência estética" (BRASIL, 2018, p. 131) a uma caricatura e aponta para o "desvendamento das camadas de sentidos" (BRASIL, 2018, p. 131) como exercícios de composição e decomposição formal, próprios de uma abordagem estruturalista da linguagem. Um simulacro da experiência estética e artítica, na sala de aula!

\section{A prática cultural da leitura e escuta da literatura}

Tal qual na tirinha de Maurício de Souza, a BNCC pressupõe uma formação do leitor literário em que textos de gêneros diversos, desencarnados dos seus suportes estão desvinculados das práticas (da linguagem) que movimentam os sentidos possíveis na apreciação estética realizada pelos alunos e na formação de seu gosto.

Ambos não colocam em questão, por exemplo, que ler um e-book (de qualidade) pressupõe leitores que podem decidir caminhos para o enredo na compreensão e produção de várias histórias; que os gestos de clicar em imagens verbais visuais e sonoras disponíveis na tela guiam os leitores, de forma rápida e simultânea, pela(s) narrativa(s). Enquanto que o leitor do impresso, diferentemente, pode parecer "um mergulhador no meio de um mar de palavras" (KIRCHOF, 2016, p. 218) que se apresentam em uma escrita linear, sequencial, em que as formas multimidias se restringem ao grafismo em preto e branco e ao colorido de imagens estáticas. (DOMINGOS, 2016). São comportamentos leitores distintos, a serem distintamente ensinados e aprendidos, no contexto das práticas culturais.

Tanto a tirinha do Maurício de Souza como o documento da BNCC não colocam em questão as diferenças, por exemplo, entre uma leitura individual e silenciosa, encontro do aluno com o texto impresso em um canto da sala de aula e a leitura/escuta compartilhada pela turma diante da encenação oral das páginas impressas, conduzida pela professora e marcada por uma imensa carga afetiva que pode ligar esses leitores. São sociabilidades distintas do ato de ler, atravessadas pela relação entre criança(s)-adulto- obra/suporte.

São modos e maneiras pelos quais os textos são lidos e significados por um gesto que só aparentemente é idêntico e que se estende muito além do acompanhamento do enredo ou do reconhecimento de rimas, ou da audição da voz assumida por um aplicativo digital.

A prática da leitura e escuta valorizada, quer no documento, quer na tirinha, ignora a formação do leitor (literário) como sendo afetada pelas finalidades e necessidades da leitura, as convenções interpretativas e disposições para o ato de ler, em distintos lugares e tempos. Limita 
o ensino da leitura e escuta a habilidades e competências destituídas dos valores que marcadamente distinguem umas práticas culturais de outras também significadas socialmente.

A prática da leitura e escuta valorizada quer no documento, quer na tirinha, desconsidera que a formação estética e literária se faz por caminhos distintos porque os sujeitos-leitores são igualmente distintos, em suas histórias de contato, familiaridade, acesso e posse dos textos literários. Desconsidera que fora da prática sociocultural (que se aprende e se ensina), aliada aos valores, mas também afetos, sensibilidades e memórias, toda prática (da linguagem) de leitura e escuta é partilhada e reconhecida pela comunidade que a usa, é ressignificada singularmente pelos leitores, em suas condições de produção de compreensão e de elaboração dos textos (literários). E qualquer documento que pressuponha a "apreciação estética/estilo", a formação do leitor literário, ou ainda, a crença de que ler é bom devem imaginar uma proposta que se faz, diversa, frequente, sistemática, intencionalmente exercitada, nas comunidades de leitores (na escola, por exemplo) que a colocam em evidência, a valorizam e a põem em movimento.

Uma prática em que os textos - na tela ou no impresso, oral ou silenciosa, encenada ou ouvida etc. - mais do que conteúdos ou composições formais e estilísticas, dependem da existência de leitores que possam deles se apossar para "inscrevê-los na memória ou para transformá-los em experiência" (Chartier, 1998, p. 153).

\section{Referências}

BITTENCOURT, Jane. Base Nacional comum curricular: uma análise a partir do ciclo de políticas. In: XIV CONGRESSO NACIONAL DE EDUCAÇÃO. IV SEMINÁRIO INTERNACIONAL DE REPRESENTAÇÕES SOCIAIS, SUBJETIVIDADE E EDUCAÇÃO. VI SEMINÁRIO INTERNACIONAL SOBRE PROFISSIONALIZAÇÃO DOCENTE. PUC-PR, Curitiba, Paraná, 2017, p. 553-569. Disponível em: https://educere.bruc.com.br/arquivo/pdf2017/24201_12678.pdf.

BRASIL. Ministério da Educação. Base nacional comum curricular. Brasília, DF: MEC, 2018. Disponível em: http://basenacionalcomum.mec.gov.br/. Acesso em: fev. 2019.

CHARTIER, Roger. A história cultural: entre práticas e representações. Lisboa: Difel, 1990.

CHARTIER, Roger. A aventura do livro do leitor ao navegador. São Paulo: Editora Unesp, 1998.

CORAZZA, Sandra M. Base Nacional Comum Curricular: apontamentos crítico-clínicos e um trampolim. REVISTA Educação - quadrimensal, Porto Alegre, v. 39, dez. 2016, s135-s144, n. esp. (supl.). Disponível em: http://dx.doi.org/10.15448/1981-2582.2016.s.23591. Acesso em: fev. 2019.

KIRCHOF, Edgar Roberto. Como ler os textos literários na era da cultura digital?. Estud. Lit. Bras. Contemp., Brasília, n. 47, p. 203-228, jun. 2016. Disponível em: http://www.scielo.br/scielo.php?script=sci_arttext\&pid=S2316-

40182016000100203\&lng=en\&nrm=iso. Acesso em: $15 \mathrm{dez} .2019$.

http://dx.doi.org/10.1590/2316-40184710

GERALDI, J. W. O ensino de língua portuguesa e a Base Nacional Comum Curricular. Revista Retratos de Escola, Brasília, v. 9, n. 17, jul./dez. 2015, p. 381-396. Disponível em: http://www.estorce.org.br. Acesso em: março 2019. 
LERNER, Delia. (trad. Ernani Rosa). Ler e escrever na escola - o real, o possível e o necessário. Porto Alegre: Artmed, 2002. (reimpressão 2007).

MARSIGLI, Ana Carolina G; PINA, Leonardo D; MACHADO, Vinicius de O. LIMA, Marcelo. A Base Nacional Comum Curricular: um novo episódio de esvaziamento da escola no Brasil. Germinal: Marxismo e Educação em Debate, Salvador, v. 9, n. 1, abr. 2017. p. 107121. Disponível em: https://portalseer.ufba.br/index.php/revistagerminal/article/view/21835. Acesso em fev. 2019.

\section{Sobre as autoras}

Norma Sandra de Almeida Ferreira. Professora colaboradora e coordenadora do grupo de pesquisa ALLE/AULA, da FE/Unicamp. Principais livros publicados: Versos para os pequeninos, de João Köpke. Uma edição fac-similar em estudo. Leitura Crítica, 2019; Um estudo sobre "Versos para os pequeninos", manuscrito de João Köpke, Mercado de Letras, 2017; A pesquisa em leitura no Brasil: 1980-1995. Komedi: Arte Escrita, 2001.

E-mail: normasandra@yahoo.com.br.

Lilian Lopes Martin da Silva. Professora e pesquisadora colaboradora da Faculdade de Educação da Unicamp, atuando junto ao Grupo 'Alfabetização, leitura e escrita/Trabalho docente e formação Inicial' onde coordena a pesquisa $A L B$ : memória. Disponível em: https://www.alleaula.fe.unicamp.br/.

E-mail: normasandra@yahoo.com.br. 